\title{
Parental Percetion of the Teaching of Sex Education to Adolescent in Secondary School in Cross River State, Nigeria
}

\section{Q $M r$ Elizabeth G. AKPAMA, Ph.D}

\begin{abstract}
This study was an ex-post facto research, design to determine parental perception of the teaching of introducing sex education to adolescents in secondary schools in Cross River State, as the area of study. Two null hypotheses were formulated on the basis of the identified major independent variables of nature of parental perception and parental literacy status. A 15-item questionnaire was developed, validated and tested for reliability. It was then administered to 400 respondents (parents-200 male, 200 female) from 20 churches in the entire state ( 7 churches from central, 7 from south and 6 from north senatorial districts). The sample was selected by stratified cluster and simple random procedure. Data was analysed using the independent t-test. Results revealed that parental perception of the teaching of sex education to adolescents in secondary schools is significantly negative; no significant difference exists between literate and illiterate parents in their perception of the teaching of sex education to adolescents in secondary schools. It was concluded that parental perception of the teaching of sex education to adolescents in secondary schools is generally negative in Cross River State. Some recommendations were enhanced as the way forward.
\end{abstract}

Keywords: adolescents, education, parents, perception, school, secondary, teaching

\section{Introduction}

Adolescents' sexuality has become an issue of controversy between the family, school and the church with each of the agents pointing accusing fingers at each other. Durojaiye (1972), Essen (1994) in their studies revealed that the introduction of sex education in the school curriculum is as a result of parents' refusal to give their adolescents the sexual information they require to help them function well in the society. Parents on their part believe that adolescents' moral decadence is an after effect of what they learn from school either through peer influences or from their teachers who are meant to act as role models. They explained that science 
adolescents spend more time at school than they do at home, the teaching of moral and ethical values should be effectively thought at school rather than teaching sex education.

Ofohia, 1991; Omoegun, 2008; Rodriguez, 2001; Ogunjimi, 2009) in their studies also revealed that adolescents sexual permissiveness is the result of the technological development experienced within the society. This school of thought holds the media and entertainment industry responsible for adolescents' moral decadence. Effiom and Ejue (1998), Walker (2004), Akpan (1974), Zabin \& Kiragu (1998) and Omoegun (1998), in their various studies affirmed that the consequences of adolescents' permissiveness towards sex are enormous. The consequences range from unwanted pregnancy, illegitimate children and contact of sexually transmitted diseases. These researchers affirm that many adolescents meet their untimely death through abortion or AIDS. Some adolescents end up having problems with their reproductive organs as a result of either wrong intake of drugs to forestall premarital pregnancy or contacted STD without timely intervention treatment.

Esu (1990) \& Isangedighi (1990) noted that the teaching of sex education to adolescents has continued to pose as a problem in Nigeria because both literate and illiterate parents share the same cultural and religious beliefs. Both Christian and Islamic religion as well as Cross River State culture forbids the teaching of sexually related matters to adolescents who are not married. These agents, the church and the home believe that it is better for adolescents not to know anything about sex before marriage. Adolescents should not practice what they know nothing about. This study attempted to define sex education; explained the rational for the introduction of sex education in the school system. Most importantly, the study investigated parental perception of the introduction of sex education to adolescents in secondary schools in Cross River State.

\section{Sex education}

This is the information and skills acquired by an individual to help the individual to deal with human sexuality. Sex education is the information provided to adolescents to help them make realistic and responsible decisions about sexual behaviours such as dating practices, courtship, mate selection and social roles (Esu, 1990). Sex education gives a detailed account on the development and understanding of the physical, mental, emotional, economic, social and psychological stages of human relations as they affect male and female relationship. 
The general objectives of sex education include:

a. To help adolescents to develop moral attitude and ideals in relation to sex and family.

b. To develop desirable habits, behaviour patterns and conduct in accordance with such attitudes and ideals.

c. To acquire knowledge of matters related to the physiology of human reproduction and aspects of family life.

d. To learn to use the proper terminology in referencing the body.

e. To become aware of some of the possible consequences and outcomes of various forms of conduct.

f. To correct and alleviate some of the common anxieties and misconceptions in the field of sexual adjustment.

g. To contribute to the emotional and social adjustment of the individuals so that he can function adequately as a member of a family and eventually as a parent (Esu, 1990).

\section{Rationale for the teaching of sex education to adolescents}

Adolescence is a period which ushers male and female into a world of pleasurable experiences. It is a period filled with excitement and the desire for sexual release. It is also a period where adolescents are filled with curiosity and exploration about the world as well as their body (UNICEF, 2011).

Esu (1990), Isangedighi (1990) explained that cultural and religious beliefs have denied adolescents the opportunity of receiving enough information about human sexuality. They opined that the inclusion of sex education in the curriculum of Nigerian secondary schools is necessary to provide information which will assist adolescents to channels their sexual drives to other creative activities until they are fully matured and prepared to engage in sexual activities. Pre-marital sex is viewed in Nigeria as a sign of immorality. It brings disgrace to those families whose adolescents are discovered to have engaged in pre-marital sex (Oloko \& Omoboye, 1993; SIECUS, 2009).

Emphasizing the importance of sex education, Isangedighi (1990); Effiom and Ejue (1998) outlined five reasons for pre-marital sexuality:

a. The nature of adolescence: Adolescence according to Isangedighi is a period marked by increased self-awareness, increased sex drive and a period of development of self-identity. Some adolescents are by nature, very inquisitive. Such adolescents would want to have an experience of 
sex. Sex education is very necessary at this stage to help such adolescents receive information on how to channel their sex drive to other creative activities until they are fully matured for it.

b. Exposure to modernity: Culture is dynamic. It changes with time and according to technological innovations. The improvement in technology has also caused a serious drift from what adolescents consider as old school values and ethics to what they call modern life. Improvement in technology also brought modernity to the media and film industry. The television, film, internet and music have significant influence on adolescents' sexuality. They tend to put in practice what they see, hear, read. These influences pose a danger to adolescents' sexual lives, hence the need for sex education.

c. Peer group influence: Adolescents experience social acceptance when they conform to the rules governing their peer relation group. Some adolescents are lured into sexual relationship by their peers who may have experienced it in one way or the other.

d. Parental attitude, care and control: Isangedighi (1990) pointed out that parents are the first group of people who set moral standards for their children. They operate as role models to their children. When parents are permissive in their parenting style, it exposes adolescents into pre-marital sex.

There are other categories of parents engage in extra marital sexual relationship without reservation. Adolescents from such families are at risk as their parents may not bother about their sexual activities. Such adolescents need sex education.

e. Eroding sexual morality: Moral laxity on the part of the adolescents can also be a reason for pre-marital sexuality. Effiom and Ejue (1998) explained that it is not uncommon to find a parent engaging in sexual activities with his daughter's girl friend. It is also not uncommon to find teachers and pastors who should be custodians of morality, engaging in sexual activities with adolescents.

In order to curb adolescents' sexuality, and to prepare the youths for a greater tomorrow, sex education to adolescents in secondary schools is therefore very important. Adolescents need sexual information to help them adjust psychologically, emotionally, socially and economically.

\section{The problem}

The problem of the study is that most parents in Cross River State are 
not fully prepared to answer questions on sexuality. Some parents are also glued to their cultural values, ethics and religious practices that they consider sex education sinful. Empirical studies have shown that even adolescents welcome sex education at various levels of the educational system. The crux of this study attempted to answer the question: How do parents perceive the introduction of sex education to adolescents in the secondary school.

\section{Research hypotheses}

Two research hypotheses were formulated to guide this study:

1. Parental perception of the teaching of sex education to adolescents in secondary schools is not significantly negative.

2. There is no significant difference between literate and illiterate parents in their perception of sex education adolescents in secondary schools.

\section{Methodology}

\section{Research design}

The ex-post facto research design was used for this study to investigate parents' perception of the teaching of sex education to adolescents in secondary schools. The ex-post facto design which means after the effect was adopted because certain factors had already been identified as having possible influence on parental perception of the leading of sex education. This is in line with Kerlingers' definition of ex-post-facto research design which he said is a systematic enquiry in which the scientist does not have direct control of independent variables because their manifestations have already occurred. The information the researcher needed already existed in its natural state and was obtained through the use of a questionnaire. The ex-post-facto design was used for the purpose of evaluation.

\section{Scope of the study}

The research area covered was the geographical expression known as Cross River State, located in the South South geo-political zone of the Federal Republic of Nigeria. The target population was parents spread across the three senatorial zones of the state: the south, central, and northern senatorial zones. The southern senatorial zone covers seven local government areas, the central senatorial zone covers six local government areas; and the northern senatorial zone covers five local government areas. Cross River State has a total of 18 local government areas involved in this study. 
Sampling and sampling technique

The study utilized a sample of 400 male and female parents (200 males and 200 females). 20 churches were randomly selected from all the churches in Cross River State. The choice of churches was based on the fact that it is in churches that parents with different cultural and religious backgrounds can be found. It is also in churches that both literate and illiterate parents can be found. Members of the selected churches were contacted to respond to questionnaire during the mid week services.

Sampling was carried out in stages, using simple random and stratified random sampling procedures. The selection was carried out at senatorial, local government areas and at church levels. In order to reflect the feelings of parents with different culture and religious back ground, the 3 senatorial zones were utilized for the study. Simple random sampling was adopted to select the zones for the study. Stratified random sampling was use to separate urban and rural areas from each of the two local government areas for each zone. Simple random sampling was used to select churches from the selected areas of the local government. A total of 20 churches were selected with break down as follows: southern zone had 7 selected churches; central zone had 7 selected churches while the northern zone had 6 selected churches. Four hundred respondents were chosen from the 20 churches for this study. Stratified randomly sampling has used in the selected churches to separate literate from illiterate parents; male and female parents. At the end of this exercise a total of 400 respondents were used with the following breakdown 136 respondent were selected from the southern zone, 134 from the central zone and 130 from the northern zone.

\section{Research instruments}

Two research instruments were constructed and used for the study: (PPTSEA) Parental perception of the teaching of sex education to adolescents. It contained 15 items and was divided into two sections. Section 'A' sought information on respondents' bio data. Section 'B' contained statements to which respondents have to indicate their perception on a 4 point Likert scale. The instrument was validated by experts in measurement and evaluation within the Faculty of Education, Cross River University of Technology. The reliability of the instrument was established through a pilot study involving 30 respondents. The split half reliability coefficient of 0.76 was obtained. 


\section{Data analysis}

Data analysis was done according to each null hypothesis that directed the study. To ease this procedure all the questionnaires that were retrieved from the respondents were first coded to yield numerical values. The codes were then extracted and stored in a data bank (a person-by-itemmatrix table); it was from this data bank that the codes were extracted and summarized into means ( $\mathrm{x}$ ) and standard deviation (SD). Hypothesis one means comparison was carried out between the hypothesized means of 12.50 and the observed (or field work mean), while for hypothesis two the independent t-test was employed in determining the difference in perception of teaching introductory sex education between literate and illiterate parents.

\section{Hypothesis one}

Parental perception of the teaching of introductory sex education to adolescents in secondary school is not significantly negative.

In analyzing this hypothesis data for mean scores on parental perception was summarized from the data bank and compared with the hypothesized mean (MU-U) which was 12.50; and then subjected to population t-test analysis, and the result presented on table 1.

\section{Hypothesis two}

There is no significant deference between literate and illiterate parents in their perception of the teaching of sex education to adolescent in secondary schools. The dependent variable in this hypothesis was parental perception of sex education, while the independent variable was the educational status of parents. The summarized data on the means ( $\mathrm{x}$ ) and standards deviations (SD) were subjected to statistical analysis, using the independent t-test procedure. The result of the analysis is presented in table 2 .

Table 1: Population t-test Analysis of Parental Perception of Teaching Sex Education to Adolescents in Schools $(\mathrm{N}=400)$

\begin{tabular}{|l|c|c|c|c|c|c|}
\hline Variables & $\mathbf{X}$ & $\mathbf{N}$ & SD & df & t-cal & P-val \\
\hline $\begin{array}{c}\text { Hypothesized/instrumentation } \\
\text { means (U): }\end{array}$ & 12.50 & & & & & \\
\hline & & 400 & 2.789 & 399 & $16.976^{*}$ & .000 \\
\hline $\begin{array}{l}\text { Sample/observed (or field) } \\
\text { mean: }\end{array}$ & 10.133 & & & & & \\
\hline
\end{tabular}

$*$ Result significant at $\mathrm{P}<.05, \mathrm{df}=399$, crit- $\mathrm{t}=1.968$, (one-tailed) 
Table 2: Independent t-test Analysis of Difference in Perception of Teaching

Sex Education in Secondary Schools by Literate

\begin{tabular}{|l|c|c|c|c|c|c|}
\hline Variables(Parental literacy) & N & X & SD & df & t-cal & P-val \\
\hline Illiterate & 200 & 20.765 & 5.264 & & & \\
\hline Literate & 200 & 20.200 & 4.849 & 398 & $1.12^{*}$ & .265 \\
\hline Total & 200 & 20.483 & 5.059 & & & \\
\hline
\end{tabular}

*Result significant at $\mathrm{P}<.05, \mathrm{df}=398$, crit- $\mathrm{r}=1.968$, (2-tailed)

\section{Result interpretation:}

From table 1, it could be observed that the calculated population t-value of $16.976^{*}$ was found to be far greater than the critical t-value of 1.968 needed for significance at 0.05 alpha level with 399 degrees of freedom. With this result the null hypothesis was rejected. This means that parental perception of the teaching of sex education to adolescents in secondary school is significantly negative. The implication of this result is that the perception of parents towards the teaching of sex education to their children (adolescents) in secondary school, Is that parents perception is generally negative, irrespective of their educational status. Furthermore, it could be inferred that there might be other factors than literacy level that are influencing the parents' perceptions such factors could be their ignorance (or lack of information about the necessity of early sex education), their (parents) religiosity) or their traditional belief system, among others.

On the other hand, observation of table 2 reveals that the calculated independent t-value of $1.12 *$ was found to be lower than the critical t-value of 1.968 needed for significance at 0.05 alpha level with 398 degrees of freedom. With this result, the null hypothesis was retained. This means that there is a no significant difference between literate and illiterate parents in their perception of the teaching of introductory sex education to adolescent in secondary schools. That is, whether literate parents do not just perceive the teaching of sex education to the youth (adolescent) as a good moral educational strategy. This further implies that there are a lot of other factors than literacy level that these parents in this area of study may be linking with introductory sex education to negatively influence on the moral standards of their children in the area.

\section{Summary of Findings}

Based on the statistical analysis of each hypothesis, the following findings 
emerged:

i) Parental perception of the teaching of sex education to adolescent in secondary schools is significantly negative that is, all parents, irrespective of their gender or education status perceptive the teaching of introductory sex education to youths as a bad, moral issues that should not be encouraged, particularly in the area of study.

ii) There is no significant difference between literate and illiterate parents in their perception of the teaching of sex education to adolescents in secondary school. This implies that factors other than literacy level (and such as ignorance, tradition and religiosity) could be contributive/influencing parental perception.

\section{Discussion of Findings}

The outcome of the results revealed that parental perception of the teaching of sex education is significantly negative. Both male and female parents perceived that teaching sex education to adolescent amounts to encouraging immorality in Cross River State. This result confirms the report of Durojaiye (1972) and Essen (1994) discoveries that sex education was introduced in schools because parents have refused to give their wards the information they need about sex, which will assist the adolescent to finding well in the society. The result of the study however, supports the findings of Ofohia (1991) who noted that schools should teach moral, ethics and values to adolescents rather than teach sex education. The research noted that this parental strong resentment towards the teaching of sex education to adolescents in secondary school is as a result of the parental strong inclination to religion doctrines and culture believes inherited from their gone parents.

The result of hypothesis 2 indicates that there is no significant difference in the perception of literate and illiterate parents in their perception of the teaching of sex education to adolescents in the secondary. The researcher noted that ignorance, tradition and religion are contributive factors towards parental perception of the teaching of sex education to adolescents. The researcher noted that both literate and illiterate parents where the same tradition and culture. Religiously, it is the literate parents who interpret written down religious doctrines to illiterate parents. This accounts for their inseparable perception towards the teaching of sex education to adolescent.

This result supports the assertion of Esu (1990) and Isangedighi (1990) when they said that culture and religion forbids adolescents knowledge 
of sexually related matters before marriage. But the tradition of Cross River State, adolescents are meant to be married as virgins. Both male and female couples are the tradition to learn and gain knowledge about sexuality related matters right from their first day of marriage. Parents strongly believed that the moral decadence experienced in the state is as a result of the sexually related knowledge which adolescent as have leant from the teaching of sex education in secondary schools.

On the contrary Rodniguez (2001), Omoegun (2008) and Ogunjimi (2009) opined that sexual permissiveness in Nigeria is as a result of technological development. They faulted the media which showcases all forms of sexuality for adolescent viewing. They also noted that sexuality before marriage is alien to Nigeria culture. They agreed that Nigeria imbibed the western culture including their sexual beliefs.

Based on the findings of this study the researched proffered the following remedial counseling implications:

1. Parents should understand that the period of adolescence is marked by increased sex derive and high level of inquisitiveness. Sex education needed at this stage to help the adolescents channel their sexual instinct to creative activities. Parents can only understand this if they are first given education on what sex education is all about.

2. Parent should also be made to understand that permissiveness in their parenting styles and peer influences can also expose adolescents to pre-marital sex. Parents need to be given adequate education on the teaching of sex education to adolescents. Inculcating the right conception in parents can change their beliefs (traditional and cultural).

3. Parents should be made to understand that in their but to embrace modernity and technology, they inject their homes with those thing such as television video sets, DSTV, computers etc that will expose adolescent to sexuality related issues. Parents turned between embracing modernity and the teaching moral values which they had or no time to do so. They should be made to understand that the schools decision to introduce sex education to adolescents is a calculated attempt to help give adolescent a bearing on their social life.

Based on these counseling implications, some recommendations were made in order to reach the parents, which have been given at the end of this article. 


\section{Conclusion}

The study revealed parents stand on the teaching of sex education to adolescents in secondary schools in Cross River State. It was discovered that traditional and cultural beliefs have an overwhelming influence on parental perception of the teaching of sex education to adolescents in school. Parents (both literate and illiterate) believed in the preservation of sex knowledge until such adolescent are married. On the contrary, parents failed to consider the fact that technological development which they have embraced also meant that there should be a shift in their belief. The government, the church and the school have been counseled to work together in other to change parental perception and also help adolescents function well in accordance with technological development.

\section{Recommendations}

1. During parents and teachers association (PTA) meeting, the counselor should liaise with the principal to introduce talks on adolescents' sexuality and the need to teach sex education to adolescents in secondary school.

2. Children preach against homosexuality and lesbianism among adolescents. The church should not also shy away from helping adolescents by organizing youth seminars for both adults and the youth on the importance of sex education.

3. Government through the media should air programmes through the television on sex education and the need for parents to collaborate with schools to prepare adolescent mind on sexuality issues.

4. During conferences and seminars, educators should present more papers on the teaching of sex education to adolescent in secondary schools. This will motivate parents as they listen to the plenary sessions to ask question for clarification on the aspect of sex education that conflict with their religious and traditional belief.

\section{References}

Akpan, E. (1974). A study of adolescents sexuality in Nigeria. West African Journal of Education, 18 (3).

Durojaiye, M. O. A. (1972). Guidance through sex education. In Durojaiye (ed). Psychological guidance of the school child. Ibadan: Vans Brothers 65-76.

Effiom, D. \& Ejue, J. B. (1998). Guidance and counselling essentials. 
Calabar: O-Kone Ile Venture.

Esu, A. E. O (1990). Sex education in Nigerian schools. In D. N. Nwachukwu (ed). Contemporary issues in Nigerian education and development. Enugu: Sam \& Star Group of Company.

Isangedighi, A. I. (1990). Adolescents sexuality in Nigerian society. In D. N. Nwachuka (ed). Contemporary issues in Nigeria education and development. Enugu: Sam \& Star Group of Company.

Ofoha, D. N. (1991). Sexuality networking among students in Lagos Island and Lagos Mainland Metropolis. Unpublished M.Ed thesis University of Lagos.

Oloko, S. B. A \& Omoboye (1993). Sexual networking among some Lagos

State adolescent Yoruba students. Journal of Health Transition Review, vol. 1.

Omoegun, O. M. \& Akanu, F. (2008). Gender and decision making pertaining to the control over ones body within established unions in Nigeria: Implication for counselling. The Counsellor.

Rodriguez, D. (2001). Sexual socialization in adolescents. New York: Norton.

SIECUS (2009). Report of public support of sexuality education. On-line. Walker, J. (2004). Parents and sex education, looking beyond the birds and the bees. Journal of Sex Education, 4, 239-254.

Zabin, L. S. \& Kiragu, K. (1998). The health consequences of adolescents sexual and fertility behaviour in sub sahara Africa. Journal of Family Planning, (2), 29. 